\title{
In Silico Identification and Comparative Genomics of Candidate Genes Involved in Biosynthesis and Accumulation of Seed Oil in Plants
}

\author{
Arti Sharma and Rajinder Singh Chauhan \\ Department of Biotechnology \& Bioinformatics, Jaypee University of Information Technology, Waknaghat, P.O. Dumehar Bani, \\ Kandaghat, Solan 173215 , India \\ Correspondence should be addressed to Rajinder Singh Chauhan, rajinder.chauhan@rediffmail.com
}

Received 5 August 2011; Revised 27 September 2011; Accepted 14 October 2011

Academic Editor: Jinfa Zhang

Copyright (C 2012 A. Sharma and R. S. Chauhan. This is an open access article distributed under the Creative Commons Attribution License, which permits unrestricted use, distribution, and reproduction in any medium, provided the original work is properly cited.

\begin{abstract}
Genes involved in fatty acids biosynthesis, modification and oil body formation are expected to be conserved in structure and function in different plant species. However, significant differences in the composition of fatty acids and total oil contents in seeds have been observed in different plant species. Comparative genomics was performed on 261 genes involved in fatty acids biosynthesis, TAG synthesis, and oil bodies formation in Arabidopsis, Brassica rapa, castor bean and soybean. In silico expression analysis revealed that stearoyl desaturase, FatB, FAD2, oleosin and DGAT are highly abundant in seeds, thereby considered as ideal candidates for mining of favorable alleles in natural population. Gene structure analysis for major genes, ACCase, FatA, FatB, FAD2, FAD3 and DGAT, which are known to play crucial role in oil synthesis revealed that there are uncommon variations (SNPs and INDELs) which lead to varying content and composition of fatty acids in seed oil. The predicted variations can provide good targets for seed oil QTL identification, understanding the molecular mechanism of seed oil accumulation, and genetic modification to enhance seed oil yield in plants.
\end{abstract}

\section{Introduction}

A major challenge mankind is facing in this century is the gradual exhaustion of the fossil energy resources. The combustion of those fossil fuels used in transportation is one of the key factors responsible for global warming and environment pollution due to large-scale carbon dioxide emissions. Thus, alternative energy sources based on sustainable and ecologically friendly processes are urgently required. At present gasoline or diesel are being largely substituted by two biofuels, bioethanol and biodiesel, capturing 90\% of the market [1]. Biodiesel is made from renewable biomass mainly by alkali-catalysed transesterification of triacylglycerols (TAGs) from plant oils [2]. Manipulation of biosynthetic pathways offers a number of exciting opportunities for plant biologists to redesign plant metabolism toward production of specific TAGs.
The biosynthesis of fatty acids in plants begins with the formation of acetyl Co-A from pyruvate. The acetyl CoA produced in plastids is activated to malonyl CoA; the malonyl group is subsequently transferred to acyl carrier protein (ACP) giving rise to malonyl ACP, the primary substrate of the fatty acid synthase complex. The formation of malonyl CoA is the committed step in fatty acid synthesis and is catalyzed by the highly regulated plastidic acetyl CoA carboxylase complex [3]. De novo fatty acid synthesis in the plastids occurs through a repeated series of condensation, reduction, and dehydration reactions that add two carbon units derived from malonyl ACP to the elongating fatty acid chain. A series of condensation reactions proceed with acetyl-CoA and malonyl-ACP, then acyl-ACP acceptors. Three separate condensing enzymes, or 3-ketoacyl-ACP synthases (KAS I-III) are necessary for the production of an 18carbon fatty acid. Three additional condensation reactions 
are required; each condensation step to obtain a saturated fatty acid that is two carbons longer than at the start of the cycle. These reactions are catalysed by 3-ketoacyl-ACP reductase (KAR), 3-hydroxyacyl-ACP dehydratase (HD), and enoyl-ACP reductase (ENR). The first desaturation step also occurs in the plastid; while the acyl chain is still conjugated to ACP, a $\Delta$ 9-desaturase converts stearoyl ACP to oleoyl ACP. Termination of fatty acid elongation is catalyzed by acyl ACP thioesterases, which are two main types in plants. The FatA class removes oleate from ACP, whereas FatB thioesterases are involved in saturated and unsaturated acyl ACPs, and, in some species, with shorter-chain-length acyl ACPs [4-6]. After release from ACP, the free fatty acids are exported from the plastid and converted to acyl CoAs. Nascent fatty acids can be incorporated into TAGs in developing seeds [4]. Oleic acid can be further desaturated to oleate acids by FAD2 [7] and FAD6 [8] in the cytosol and the plastid, respectively. Cytosolic and plastid $\omega-3$ desaturations that result in the production of linolenic acids are catalyzed by FAD3 [9] and FAD7 [10], respectively. Fatty acids can be incorporated into TAGs in developing seeds in a number of ways. For example, a series of reactions known as the Kennedy pathway results in the esterification of two acyl chains from acyl CoA to glycerol-3-phosphate to form phosphatidic acid (PA) and, following phosphate removal, diacylglycerol (DAG). A diacylglycerol acyltransferase (DGAT), using acyl CoA as an acyl donor, converts DAG to TAG. Two classes of DGAT enzymes have been isolated $[11,12]$, and orthologs have been identified in numerous plant species. DAG and phosphatidylcholine (PC) are interchangeable via the action of cholinephosphotransferase, suggesting a route for the flux of fatty acids into and out of PC. Acyl chains from PC can be incorporated into TAG, either via conversion back to DAG or by the action of a phospholipid diacylglycerol acyltransferase (PDAT) that uses PC as an acyl donor to convert DAG to TAG. There are two predominant seed oil storage proteins in plants: caleosin and oleosin. TAG assembled in these storage proteins form oil bodies in seeds.

The fatty acid composition of seed oil varies considerably both between species and within species. The variation of fatty acids occurs both in chain length and degrees of desaturation. Consequently, the fuel properties of biodiesel derived from a mixture of fatty acids are dependent on the composition of fatty acids in seed oil. Altering the fatty acid profile can, therefore, improve fuel properties of biodiesel such as cold-temperature flow characteristics, oxidative stability, and NOx emissions [13].

Fatty acid biosynthetic pathway is highly conserved in plants, but there are significant variations in fatty acid contents and composition in plants (Table 1). What determines differences in the contents and composition of fatty acids and subsequently the total oil yield in the seeds is not understood. The availability of whole genome sequences, ESTs, and individual gene sequences from different oil rich plant species provide an opportunity to investigate what differences in the structure and sequences of genes determine variation in contents and composition so as to identify distinguishing gene signatures to assist in genetic improvement of crop plants either through marker-assisted breeding or by metabolic engineering [32]. Tanhuanpää et al. [33] developed an allele-specific PCR marker for oleic acid by comparing the wild-type and high-oleic allele of the FAD 2 gene locus in spring turnip rape (Brassica rapa ssp. oleifera). The accumulation of ricinoleic acid in transgenic Arabidopsis seeds was doubled by expressing the castor FAH12 hydroxylase in a FAD 2/FAE1 mutant [34]. The FatA and FatB genes of castor bean were heterologously expressed in Escherichia coli for biochemical characterization after purification, resulting in high catalytic efficiency of RcFatA on oleoyl-ACP and palmitoleoyl-ACP and high efficiencies of RcFatB for oleoyl-ACP and palmitoyl-ACP. The expression profile of these genes displayed the highest levels in expanding tissues that typically are very active in lipid biosynthesis such as developing seed endosperm and young expanding leaves [35]. Arabidopsis thaliana gene diacylglycerol acyltransferase (DGAT) coding for a key enzyme in TAG biosynthesis was expressed in tobacco under the control of a strong ribulose-biphosphate carboxylase small subunit promoter. This modification led up to a 20fold increase in TAG accumulation in tobacco leaves and translated into an overall twofold increase in extracted fatty acids up to $5.8 \%$ of dry biomass in Nicotiana tabacum [36]. Dimov and Mollers [37] tested genetic variation for saturated fatty acid content in two sets of modern winter oilseed rape cultivars (Brassica napus L.) in field experiments under typical German growing conditions. They observed highly significant genetic differences among the cultivars for total saturated fatty acid content, which ranged from $6.8 \%$ to 8.1\%. Singh et al. [38] constructed genetic map using AFLP, RFLP, and SSR markers for oil palm. They detected quantitative trait loci (QTLs) controlling oil quality (measured in terms of iodine value and fatty acid composition) and identified significant QTLs associated with iodine value (IV), myristic acid (C14:0), palmitic acid (C16:0), palmitoleic acid (C16:1), stearic acid (C18:0), oleic acid (C18:1), and linoleic acid (C18:2) content. The Brassica napus mutant line DMS100 carrying a G-to-A base substitution at the $5^{\prime}$ splice site of intron 6 in FAD 3 had reduced C18: 3 content in oil seeds [39]. These studies suggest that the comparative analysis of oil biosynthesis and accumulation genes is a suitable strategy to investigate the molecular basis of oil content and composition variation in seed oils of different plant species. Additionally, these variations can be used to develop functional markers for increasing selection efficiency by marker- assisted selection in plant breeding.

In the present study, four plant species, Arabidopsis, Brassica, soybeans, and castor bean were considered for comprehensive analysis of fatty acid biosynthesis genes due to the availability of their genome sequences and several ESTs collections. Moreover, soybeans and brassicas are the biggest source of plant oil in the world, whereas castor bean contains unusual fatty acid ricinoleate that have chemical properties useful for industrial applications. The total seed oil contents of Arabidopsis, castor bean Brassica, and soybean are 30$37 \%, 40-45 \%, 30-40 \%$, and 15-20\%, respectively (Table 2) [28-31]. Plant oils are mostly composed of five common fatty acids, namely, palmitate $(16: 0)$, stearate $(18: 0)$, oleate $(18: 1)$, linoleate $(18: 2)$ and linolenate $(18: 3)$, although, 
TABLE 1: Variations for fatty acids and TAG biosynthesis pathway genes associated with high oil content in different plant species.

\begin{tabular}{|c|c|c|c|c|}
\hline Targeted Genes & Descriptions of variations & $\begin{array}{c}\text { Gene regions } \\
\text { harboring variations }\end{array}$ & Plant/organism & References \\
\hline FAD 2, FAD 3 & $\begin{array}{l}\text { SNP for high oleic acid and low linolenic } \\
\text { acid }\end{array}$ & Exon & Brassica & Hu et al., 2006 [14] \\
\hline $\begin{array}{l}\text { Stearoyl-ACP } \\
\text { desaturase }\end{array}$ & SNP for high stearic acid & Exon & Soybean & $\begin{array}{l}\text { Zhang et al., } 2008 \\
{[15]}\end{array}$ \\
\hline FAD 2 & SNPs for high oleic acid & Exon & Peanut & López et al., 2000 [16] \\
\hline FAD 3 & SNP for low linolenic acid & Intron-Exon junction & Soybean & Bilyeu et al., 2005 [17] \\
\hline KAS I & $\begin{array}{l}\text { SNPs and Indel associated with oleic acid } \\
\text { content }\end{array}$ & 5'UTR, Exon, Intron & Soybean & Ha et al., $2010[18]$ \\
\hline $\begin{array}{l}\text { KAS III, ACCase, } \\
\text { Stearoyl-ACP } \\
\text { desaturase, DGAT }\end{array}$ & $\begin{array}{l}\text { Indels, SNPs and SSRs associated with } \\
\text { variation in composition and concentration } \\
\text { of oil }\end{array}$ & - & Maize & Yang et al., 2010 [19] \\
\hline FAD 2 & $\begin{array}{l}3 \text { base pair variation leads to change in } \\
\text { amino acid which contribute to high oleate } \\
\text { content in oil }\end{array}$ & Exon & Peanut & $\begin{array}{l}\text { Bruner et al., } 2001 \\
{[20]}\end{array}$ \\
\hline DGAT1 & $\begin{array}{l}3 \text { bp Insertion leads to high oleic acid } \\
\text { content }\end{array}$ & Exon & Maize & $\begin{array}{l}\text { Zheng et al., } 2008 \\
{[21]}\end{array}$ \\
\hline FAD 2 & SSR linked to oleic acid content & & Soybean & $\begin{array}{l}\text { Bachlava et al., } 2008 \\
{[22]}\end{array}$ \\
\hline FAD 3 & $\begin{array}{l}\text { Deletion in soybean FAD } 3 \text { leads to reduced } \\
\text { linolenate }\end{array}$ & Exon & Soybean & Anai et al., 2005 [23] \\
\hline KAS III & $\begin{array}{l}\text { SNP associated with high palmitic acid } \\
\text { content }\end{array}$ & Exon & Soybean & $\begin{array}{c}\text { Aghoram et al., } 2006 \\
{[24]}\end{array}$ \\
\hline $\begin{array}{l}\text { Stearoyl-ACP } \\
\text { desaturase }\end{array}$ & SSRs associated with high stearic acid & - & Soybean & $\begin{array}{l}\text { Spencer et al., } 2003 \\
{[25]}\end{array}$ \\
\hline $\begin{array}{l}\text { Stearoyl-ACP } \\
\text { desaturase }\end{array}$ & $\begin{array}{l}\text { SSRs and INDELs associated with high } \\
\text { stearic acid }\end{array}$ & - & Sunflower & $\begin{array}{l}\text { Pérez-Vich et al., } 2006 \\
{[26]}\end{array}$ \\
\hline FatB & $\begin{array}{l}\text { Deletions associated with low palmitic acid } \\
\text { content }\end{array}$ & Exons and Introns & Soybean & $\begin{array}{l}\text { Cardinal et al., } 2007 \\
\text { [27] }\end{array}$ \\
\hline
\end{tabular}

TABLE 2: Fatty acid composition of four plant species.

\begin{tabular}{|c|c|c|c|c|}
\hline $\begin{array}{l}\text { Fatty acid composition } \\
(\%)\end{array}$ & Arabidopsis [28] & Castor bean [29] & Brassica [30] & Soybean $[31]$ \\
\hline Palmitic acid & 8.7 & 2.0 & 1.5 & $7-11$ \\
\hline Stearic acid & 3.6 & 1.0 & 0.4 & $2-6$ \\
\hline Oleic acid & 15.0 & 7.0 & $\underline{22.0}$ & $\underline{22-34}$ \\
\hline Linolenic acid & 29.0 & - & 6.8 & $5-11$ \\
\hline Linoleic acid & 19.2 & 5.0 & 14.2 & $\underline{43-56}$ \\
\hline Ricinoleic acid & - & $\underline{86-90}$ & - & - \\
\hline Others & 24.5 & - & $\underline{47}($ Erucic $)$ & - \\
\hline Total oil content & $30-37$ & $45-50$ & $33-40$ & $15-20$ \\
\hline
\end{tabular}

depending on the particular species, longer or shorter fatty acids may also be major constituents. These fatty acids differ from each other in terms of acyl chain length and number of double bonds, leading to different physical properties. Here we put forward the questions (1) whether there are common variations in genes, if any, which contribute to increased seed oil content in plants? (2) Which are the major genes responsible for the higher amounts of five fatty acids mentioned above in different plant species? For answering these questions the present study aimed at (1) the identification of candidate genes for fatty acid biosynthesis,
TAG synthesis and oil body formation proteins in plant species under study, (2) the comparative structure analysis of these candidate genes, (3) the in silico identification of sequence variations in fatty acid biosynthesis genes, and (4) the in silico association of sequence variations in candidate genes for oil content and composition.

\section{Materials and Methods}

2.1. Retrieval of Sequences. Thirty-two genes involved in the biosynthesis and storage of fatty acids were retrieved from 
Arabidopsis database (http://lipids.plantbiology.msu.edu/) by referring to the comprehensive lipid gene catalog provided by Beisson et al. [40]. The selected genes covered all the major biochemical events in the biosynthesis and storage of fatty acids $[41,42]$. The protein sequences of these genes were used as query against castor bean database in TIGR (http://blast.jcvi.org/er-blast/index .cgi?project=rca1) and soybean database in soybase (http://soybase.org/). Full-length coding sequences of Brassica were downloaded from GenBank (http://www .ncbi.nlm.nih.gov/genbank/GenbankSearch.html). Protein function domains were examined with "CDD" from NCBI (http://www.ncbi.nlm.nih.gov/Structure/cdd/cdd.shtml).

2.2. Prediction of Gene Structures. Gene models for castor bean and soybean genomes were downloaded from Phytozome (http://www.phytozome.net/). The Arabidopsis gene models were downloaded from TAIR (http://www .arabidopsis.org/). Arabidopsis, castor bean, Brassica. Rapa, and soybean sequences were further annotated for gene models (open reading frames, including the 5'UTRs and 3'UTRs) using gene prediction algorithms of FGenesH (http://linuxl.softberry.com/berry.phtml?topic=fgenesh\&group $=$ programs\&subgroup $=$ gfind) $[43-45] \quad$ (see Table 1 of the Supplementary Material available online at doi:10.1155/2012/914843). Sequence identity among Brassica rapa, castor bean, soybean, and Arabidopsis genes was confirmed using ClustalW in MegAling in DNASTAR (DNASTAR Inc., Madison, WI, USA). The in silico expression status of candidate genes belonging to different families was searched with an e-value cutoff 0.0 in the ESTdb of NCBI (National Centre for Biotechnology Information) at http://www.ncbi.nlm.nih.gov/BLAST/ and TIGR (The Institute of Genomic Research) at http://blast.jcvi.org/erblast/index.cgi?project=rca1.

\section{Results}

3.1. Comparative Genomics of Fatty Acid Biosynthesis Genes in Major Oil Seed Plant Species. The fatty acid biosynthesis pathway includes 32 gene families involved in the conversion of acetyl Co-A into different fatty acids and their storage in oil bodies. A total of 68 protein sequences were retrieved for 32 gene families from the comprehensive lipid gene catalog of Arabidopsis [40] and functional domains were identified for each gene family. The 68 protein sequences from Arabidopsis were queried for fatty acid biosynthesis genes in Brassica rapa, soybean, and castor bean databases. A total of 261 genes belonging to 32 gene families were identified and retrieved from four plant species, out of which, 68 were from Arabidopsis, 62 from Brassica rapa, 55 from castor bean, and 76 from soybean (Table 3 ). Detailed gene structures, exonintron coordinates of each gene are given in Supplementary Table 1.

3.2. Expression Status of Fatty Acid Biosynthesis Genes. In silico expression analysis revealed that for 32 gene families, ESTs were detected for 68 genes in Arabidopsis, 62 genes in

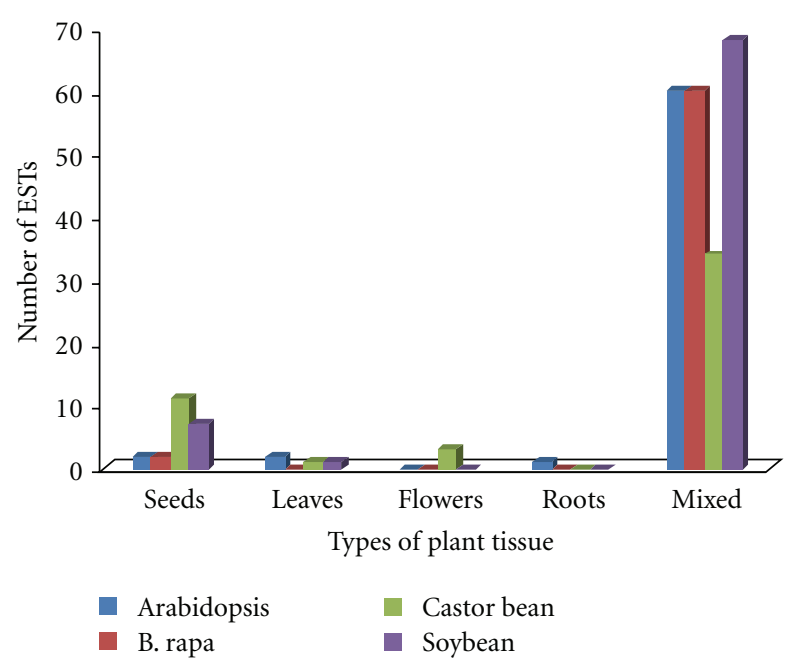

FIGURE 1: In silico transcript abundance (based on matching ESTs available in the database) of oil biosynthesis and accumulation genes in different tissues.

Brassica, 49 genes in castor bean, and 76 genes in soybean (Figure 1). Thirteen genes of Arabidopsis, 15 from castor bean, 8 from soybean, and 2 from Brassica showed tissue preferential expression patterns as per their identities to ESTs from tissue-specific libraries. Twenty-two genes from four plant species were expressed in seeds, 4 in leaves, 3 in flower, and 1 in roots (Table 4). FAD 2 and one homolog of Stearoyl desaturase gene had maximum seed ESTs in castor bean.

\subsection{Comparative Analysis of Gene Structures in Different Plant} Species. Comparative genomics of fatty acid biosynthesis genes was done to understand as what determines differences, if any, for variations in contents and compositions of fatty acids in different plant species. The gene structure analysis revealed that the exon-intron structure of fatty acid biosynthesis genes in castor bean and soybean gene homologs shared more structure similarity in comparison to Arabidopsis fatty acid biosynthesis genes. However, insertion, deletion, and intron size variations were found in castor bean and soybean genes with reference to Arabidopsis. Fatty acid biosynthesis genes of Brassica rapa were not analyzed for gene structure because for most of the Brassica genes only coding DNA sequences were available in the GeneBank.

Conversion of acetyl Co-A to malonyl Co-A by acetyl carboxylase (ACCase) is the most committed step in fatty acid biosynthesis. Exon/intron number and CDS length for ACCase gene was almost same between castor bean (31 exons) and soybean (33 exons), whereas slightly less in Arabidopsis (26 exons). Comparative structural analysis revealed that homomeric ACCase gene from Arabidopsis (1-26 exons) showed microsynteny with castor bean (631 exons) and soybean (6-33 exons), with a 3 bp deletion in 8 th and 26th exons of castor bean, $3 \mathrm{bp}$ deletion and $3 \mathrm{bp}$ insertion in 29th and 31st exons of soybean, and a $12 \mathrm{bp}$ insertion in 24th and 26th exons of castor bean and soybean, respectively. First five exons of homomeric 


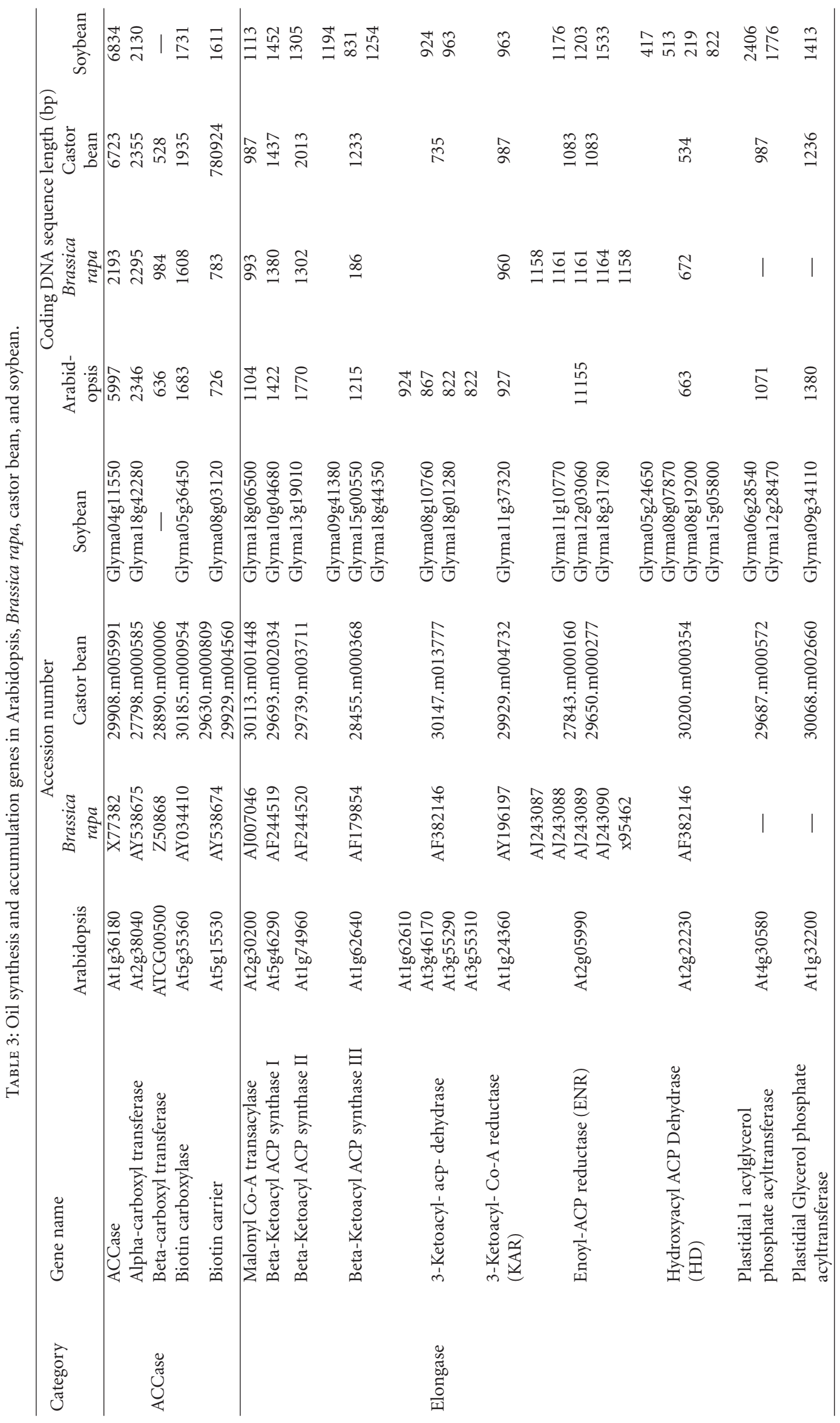




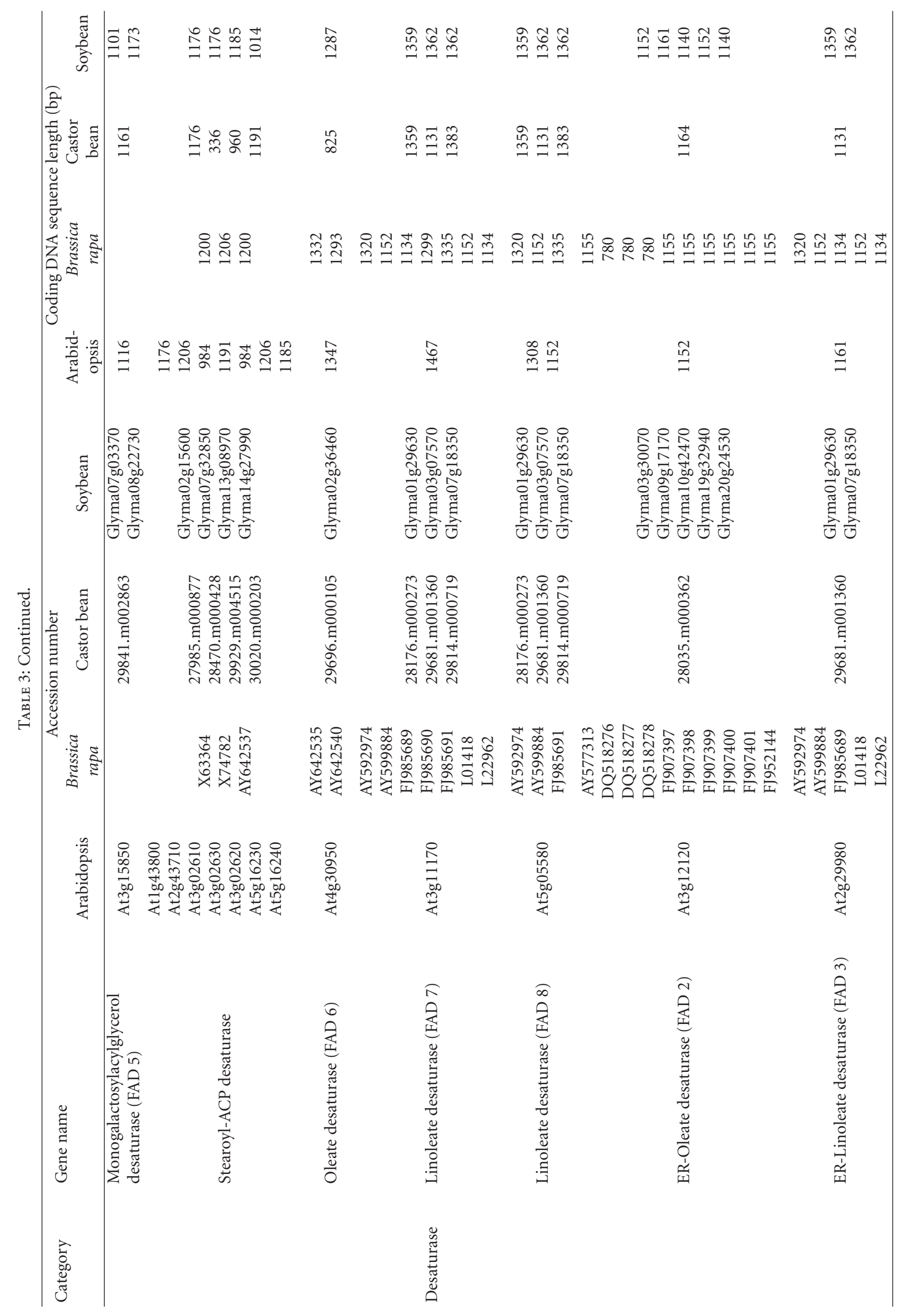




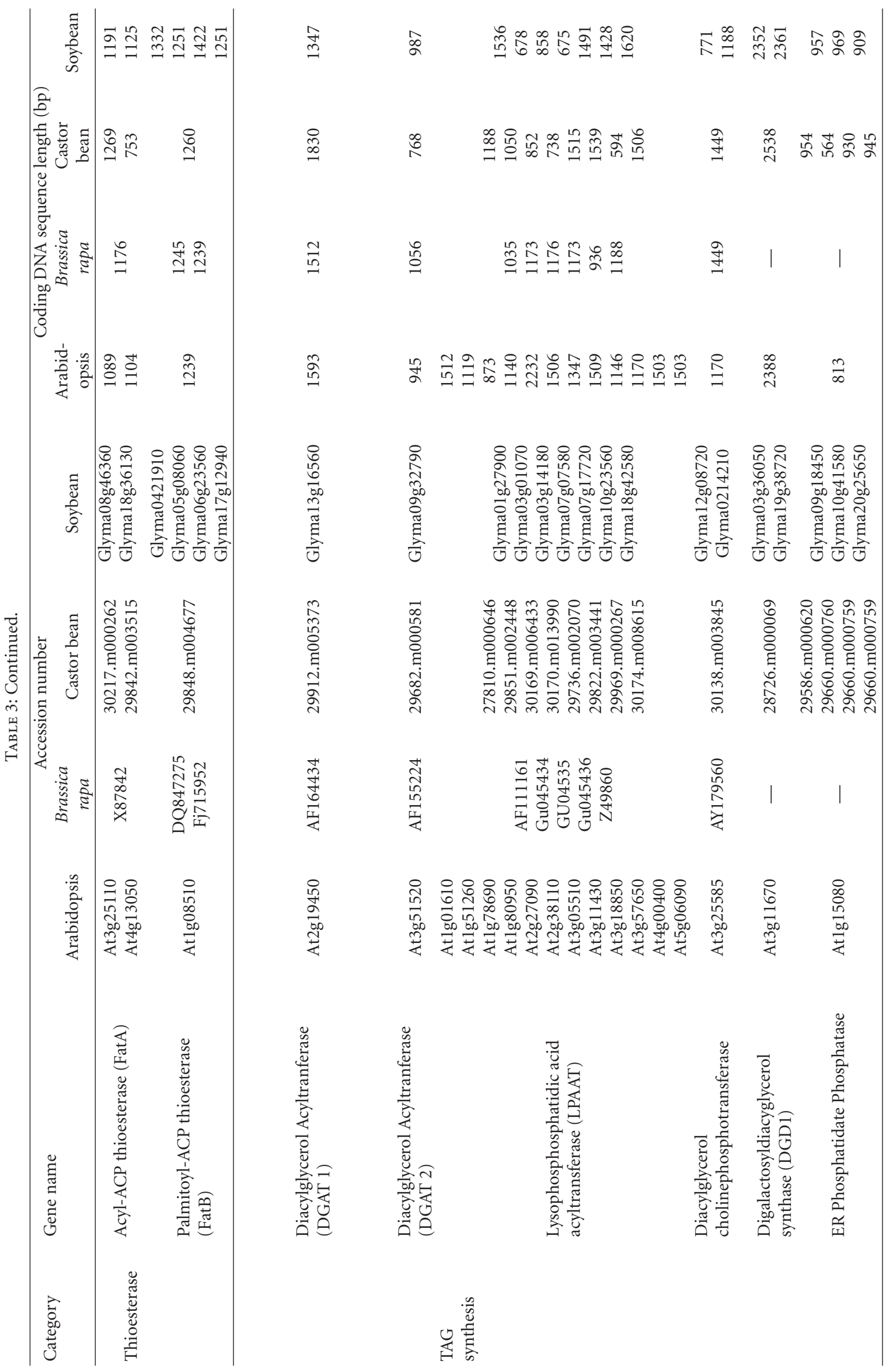




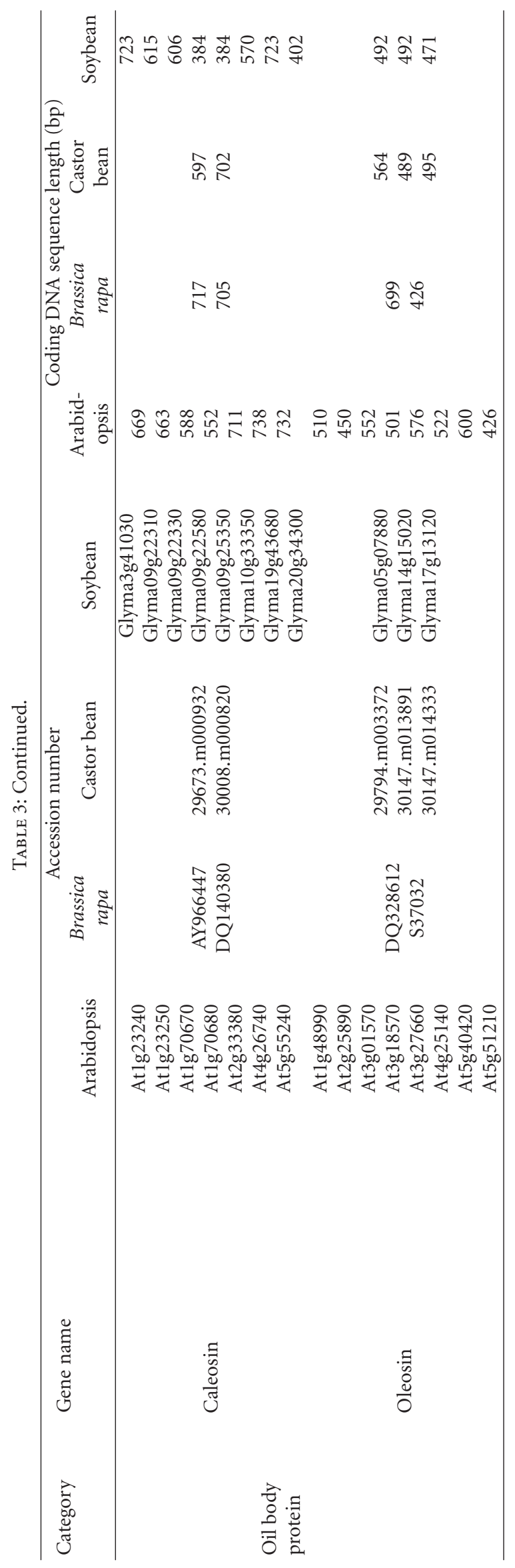


TABLE 4: In silico expression status of fatty acids biosynthesis and accumulation genes.

\begin{tabular}{|c|c|c|c|c|c|}
\hline \multirow{2}{*}{ Tissue } & \multirow{2}{*}{ Gene } & \multicolumn{4}{|c|}{ Accession no. } \\
\hline & & Arabidopsis & B. rapa & Soybean & Castor bean \\
\hline \multirow{12}{*}{ Seeds } & Alpha carboxyltransferase & & & & 27798.m000585 \\
\hline & Enoyl ACP reductase & & & & 27843.m000160 \\
\hline & Stearoyl desaturase & & $\mathrm{X} 74782$ & Glyma13g08970 & 27985.m000877 \\
\hline & FAD-2 & & & Glyma10g42470 & 28035.m000362 \\
\hline & $\begin{array}{l}\text { ER Phosphatidate } \\
\text { Phosphatase }\end{array}$ & & & & 29660.m000760 \\
\hline & DGAT 2 & & & Glyma17g06120 & 29682.m000581 \\
\hline & FatB & & & Glyma17g12940 & 29842.m003515 \\
\hline & Oleosin & & S37032 & Glyma14g15020 & $30147 . \mathrm{m} 014333$ \\
\hline & Oleosin & At5g40420 & & Glyma17g13120 & 30147.m013891 \\
\hline & Oleosin & & & & 29794.m003372 \\
\hline & Hydroxyacyl ACP dehydrase & & & & $30200 . \mathrm{m} 000354$ \\
\hline & Caleosin & At5g55240 & & Glyma20g34300 & \\
\hline \multirow[t]{4}{*}{ Leaves } & FatB & & & & 29848.m004677 \\
\hline & LPAAT & & & Glyma07g07580 & \\
\hline & 3-Ketoacyl-acn-debydrace & At3g55290 & & & \\
\hline & & At3g55310 & & & \\
\hline \multirow[t]{3}{*}{ Flowers } & DGD1 & & & & 28726.m000069 \\
\hline & Beta- carboxyl transferase & & & & 28890.m000006 \\
\hline & ACCase & & & & 29908.m005991 \\
\hline Roots & Stearoyl desaturase & At3g02620 & & & \\
\hline Roots + flowers & Stearoyl desaturase & At3g02610 & & & \\
\hline Seed + flowers & Oleosin & At1g48990 & & & \\
\hline \multirow{6}{*}{ Leaves + flowers } & FAD 7 & At3g11170 & & & \\
\hline & Oleosin & At2g25890 & & & \\
\hline & & At3g 18570 & & & \\
\hline & & Atlg23240 & & & \\
\hline & Caleosin & Atlg23250 & & & \\
\hline & & At4g26740 & & & \\
\hline
\end{tabular}

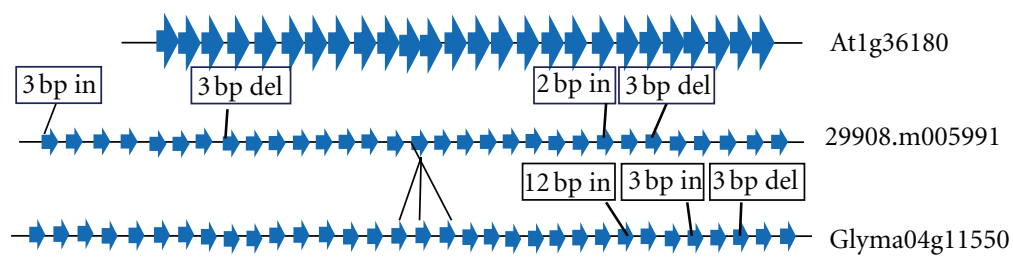

Figure 2: Structure of ACCase gene in Arabidopsis (26 exons), castor bean (31 exons), and soybean (33 exons); thick arrows and thin lines represented exons and introns, respectively. Arabidopsis 1-26 exons showed identity to 6 to 31 st and 6 to 33rd exons of castor bean and soybean, respectively; 16th exon of castor bean showed identity to three exons of soybean (16th, 17th, and 18th). A 3 bp deletion (del) in the 8th and 26th exons of castor bean, $3 \mathrm{bp}$ deletion and $3 \mathrm{bp}$ insertion (in) in the 31st and 29th exons of soybean, and a $12 \mathrm{bp}$ insertion in the 24th and 26th exons of castor bean and soybean, respectively. At1g36180: Arabidopsis ACCase gene; 29908.m005991: Castor bean ACCase gene; Glyma04g11550: Soybean ACCase gene. 


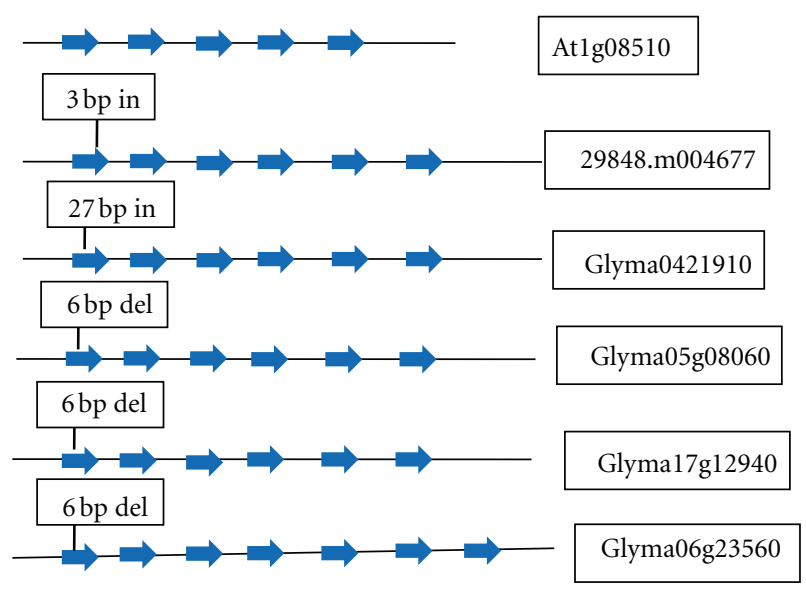

Figure 3: Structure of FatB (palmitoyl thioesterase) gene in Arabidopsis (At1g08510), castor bean (29848.m004677), and four soybean homologs (Glyma0421910, Glyma05g08060, Glyma17g12940, and Glyma06g23560). The 5th exon of FatB in Arabidopsis showed homology to the 6th exon of one of the homologs of soybean (Glyma04g21910) and last two exons (6th and 7th) of another homolog of soybean (Glyma06g23560), whereas 6th exon of castor bean showed homology to the 6th exons of other two homologs of soybean (Glyma05g08060 and Glyma17g12940).

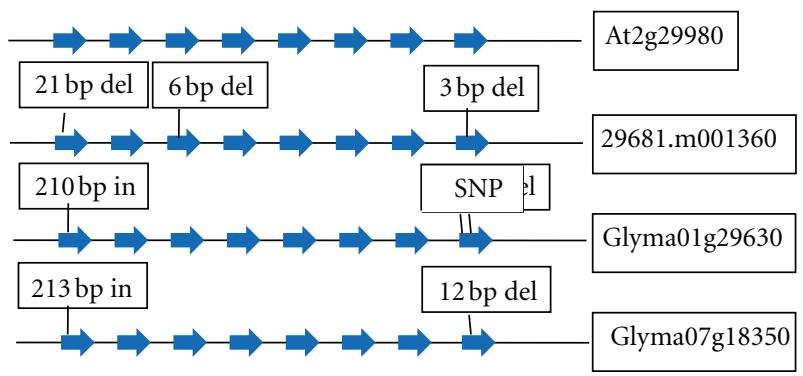

Figure 4: Structure of FAD 3 (linoleoyl desaturase) gene in Arabidopsis (At2g29980), castor bean (29681.m001360), and two soybean homologs (Glyma01g29630, Glyma07g18350). Exon/intron numbers are conserved in FAD 3 while variation in sizes was observed in the first and last exons. SNP identified in the 6th exon of soybean homolog (Glyma01g29630) was reported to be associated with low linolenic acid content [17].

ACCase in castor bean and soybean (missing in Arabidopsis) showed colinearity for exon size, with the exception of a $3 \mathrm{bp}$ insertion in the first exon of castor bean gene. Sixteenth exon of ACCase in castor bean showed sequence identity to 3 exons (16th, 17th, and 18th) of soybean (Figure 2).

Two distinct classes of thioesterases, FatA and FatB, are responsible for release of fatty acids from ACP by thioesterases. FatA gene structure was diverse with respect to exons number (varying from 5 to 11) among four plant species. Two homologs of FatA gene were present in Arabidopsis, castor bean, and soybean, whereas FatB gene had 4 homologs in soybean. The first exon of FatB gene had an insertion of $3 \mathrm{bp}$ in castor bean and $27 \mathrm{bp}$ insertion in one of soybean homologs (Glyma0421910) and other three homologs of soybean (Glyma05g08060,
Glyma17g12940, and Glyma06g23560) had 6bp deletion compared to Arabidopsis (Figure 3). An $69 \mathrm{bp}$ insertion of one exon was present in FatB genes of castor bean and soybean but was absent in Arabidopsis. The last exon of FatB (5th exon) in Arabidopsis showed homology to the last exon (6th exon) of one of the homologs of soybean (Glyma04g21910) and last two exons (6th and 7th) of another homolog of soybean (Glyma06g23560), whereas last exon of castor bean showed homology to the last exon of other two homologs of soybean (Glyma05g08060 and Glyma17g12940).

Stearoyl ACP desaturase gene had maximum number of homologs (6 in Arabidopsis, 3 in Brassica, 4 in soybean, and 4 in castor bean) in fatty acid desaturase category of enzymes. Oleoyl desturase $(\mathrm{Fad} 2)$ and Linoleate desaturase (Fad3) genes showed more relatedness in relation to number and sizes of exons and introns in each homolog among four plant species. Oleoyl desaturase (FAD 2) had only one exon in Arabidopsis, castor bean, and soybean with an insertion of $12 \mathrm{bp}$ in the exon of castor bean and $9 \mathrm{bp}$ insertion in the exon of one homolog of soybean (Glyma09g17170). FAD 3 gene structure was conserved with respect to exon-intron number and size between Arabidopsis, castor bean, and soybean except for first and last exons. A $21 \mathrm{bp}$ deletion in the first exon of castor bean (29681.m001360) and an insertion of 210 and 213 bp was observed in two homologs of soybean (Glyma01g29630 and Glyma07g18350), respectively. Two deletions of 3 and 12 bp were observed in the last exon (8th exon) of castor bean and soybean, respectively. A deletion of 6 bp was observed in the 3rd exon of FAD 3 of castor bean. An $\mathrm{SNP}(\mathrm{G} \rightarrow \mathrm{A})$ was also identified at the exon-intron junction of FAD 3 gene in the 3rd exon of one homolog of soybean (Glyma01g29630) with respect to castor bean, Arabidopsis, and other homologs of soybean (Figure 4).

The DGAT gene involved in TAG (Tri-acyl Glyceride) synthesis has two isoforms, DGAT-1 and DGAT-2. These two genes showed variation in number and sizes of exons and introns. DGAT-1 gene had 15 exons in Arabidopsis, 13 exons in castor bean, and 16 exons in soybean. DGAT2 had 8 exons in Arabidopsis and castor bean and 7 exons in soybean. The detailed comparative genomics of fatty acid biosynthesis genes in 4 oil seed plant species provided insights to undertake identification and utilization of castor bean fatty acid biosynthesis genes and sequence variations for the development of candidate gene markers in Jatropha.

Fatty acid biosynthesis genes showed evolutionary relatedness but there is no synteny in gene order and position of genes on the chromosomes. Location of genes on chromosomes in Arabidopsis and soybean is given in Supplementary Table 2.

\section{Discussion}

In general, plant oil biosynthesis mostly follows the common biosynthetic pathways for fatty acids in the plastid as well as TAG in the endoplasmic reticulum (ER) and the oil further accumulates in oil bodies. However, there are significant differences for content and composition of seed oil in 
different plant species. Using comparative genomics, we tried to infer the effect of change in gene structure differences on oil content in different plant species. In this study, 261 genes involved in biosynthesis and accumulation of seed oil were identified in four oil seed plant species, Arabidopsis, Brassica, castor bean, and soybean. The genes corresponded to six different categories (ACCase, desturase, elongase, thioesterase, TAG synthesis and oil body proteins). Gene families corresponding to these six categories of enzymes had multiple copies in plant species with the exception of homomeric ACCase.

In higher plants, many proteins and enzymes are encoded by gene families, and in Arabidopsis, it has been estimated that $20 \%$ of genes are members of gene families [46]. The existence of gene families can sometimes reflect additional levels of genetic control or isoforms of proteins with specific functions. Therefore, it is of interest to detect potential gene families involved in the fatty acid biosynthesis pathway. There is a possibility that different copies of fatty acid biosynthesis genes are present in low oil content genotypes which gives leaky phenotypes as in the case of starch biosynthesis pathway where different copies of genes were responsible for low, medium, and high amylase contents in rice [47].

The oil biosynthesis may be limited by the production of fatty acids [48], which is regulated by acetyl CoA carboxylase (ACCase). Reduction of ACCase activity lowered (1.5-16\%) the fatty acid content in transgenic seeds [49]. Conversion of acetyl Co-A to malonyl Co-A by acetyl carboxylase (ACCase) is the most committed step in fatty acid biosynthesis. ACCase of castor bean and soybean showed microsynteny to Arabidopsis, with a $3 \mathrm{bp}$ deletion in 8 th and 26th exons in castor bean, $3 \mathrm{bp}$ deletion and $3 \mathrm{bp}$ insertion in 29th and 31 st exons in soybean and a $12 \mathrm{bp}$ insertion in 24th, and 26th exons of castor bean and soybean, respectively with respect to Arabidopsis. These sequence variations in ACCase genes may be possibly influencing the variations in fatty acid composition and content in seed oil among Arabidopsis, castor bean, and soybean, as fatty acid content and composition was altered in many plant species with the variations in sequences or expression of ACCase gene $[19,50]$. Yang et al. [19] identified two SNPs $(T \rightarrow G, G \rightarrow$ A) in ACCase gene which lead to increase (1.3\%) in oleic acid, lenolenic acid, and lenoleic acid content in maize. Addition of a plastid transit sequence targeted the introduced ACCase protein to chloroplasts, ultimately resulting in a $5 \%$ increase in seed oil of rapeseed [50]. The insertion or deletion identified in our analysis between Arabidopsis, castor bean, and soybean might be responsible for reduction or enhancement of ACCase activity, which is associated with the variations in total fatty acid composition in seed oil among these plant species.

Studies in transgenic plants have demonstrated that thioesterases contribute to the regulation of fatty acid chain length [51]. Typically, FatB accepts saturated acyl-ACP substrates of varying length, while FatA is specific to unsaturated fatty acids and acts on C18:1, oleic, acyl-ACPs [51]. In Brassica napus and Arabidopsis, genetic engineering of AcylACP thioesterase (FatB) resulted in maximum increase of
$58 \%$ in palmitic acid content $[52,53]$. Preventing the release of saturated fatty acids from ACP by downregulating FatB, which encodes a palmitoyl ACP thioesterase, lowered the levels of saturated fatty acids [54]. Variations in palmitate content in seed oil in plant species can be related to the variations in FatB gene [27, 52, 53]. Cardinal et al. [27] identified deletion in exon-inrton junction in one homolg of FatB gene which was associated with low palmitic acid content in soybean cultivar Century (N79-2077 and N932008). Palmitate content was $\sim 8 \%$ in Arabidopsis [55], $\sim 2 \%$ in castor bean [56] and $7-11 \%$ in soybean [57]. Variations in the amount of palmitic acid in the seeds of Arabidopsis, castor bean, and soybean might be due to deletions in first exon of FatB gene, which can be further utilized for identification of markers associated with high level of palmitate (saturated fatty acid) in total seed oil in plant species desired for biodiesel purpose.

Soybean lines with high levels of oleic acid (85\%) and low levels of saturated fatty acids (6\%) have been developed using a transgenic strategy that results in downregulation of two genes, FAD 2, and FatB involved in fatty acid synthesis. Downregulation of the FAD 2 gene, encoding a $\Delta 12$ fatty acid desaturase, prevented the conversion of oleic acid to polyunsaturated fatty acids, resulting in increased levels of oleic acid. Additionally, preventing the release of saturated fatty acids from acyl carrier protein (ACP) by downregulating FatB gene, which encodes a palmitoyl ACP (acyl carrier protein) thioesterase, lowered the levels of saturated fatty acids [54]. Hu et al. [14] sequenced the FAD 2 gene fragment from the mutant line DMS100 and wild-type line Quantum of Brassica napus, and identified a single nucleotide mutation $(\mathrm{C} \rightarrow \mathrm{T})$ in the FAD 2 gene. This particular mutation created a stop codon (TAG) leading to premature termination of the peptide chain during translation which leads to high oleic acid content in mutant line DMS100. B. napus mutant line DMS100 carrying a G-to-A substitution at the $5^{\prime}$ splice site of intron 6 in FAD 3 had reduced lenolenic acid content in seed oil [39]. In our analysis insertions or deletions in FAD 2 and FAD 3 genes of soybean might be the possible causes of higher oleate and linoleate content in high oil yielding soybean genotypes. Higher amount of ricinoleic acid in castor bean can be due to an insertion in the FAD 2 gene resulting in higher level of oleic acid because oleic acid is further utilized as a substrate by fatty acid hydroxylase (FAH) to convert oleate to ricinoleate. Low level of linoleate in castor bean oil may be due to a deletion in the 3rd exon of FAD 3 gene because each copy of FAD 3 in Arabidopsis and soybean is conserved.

In our analysis, the acyl-CoA:diacylglycerol acyltransferases (DGAT) gene was highly diverse, which might be involved in the overall variation in triacylglycerols in the oil among the plant species as it is a key enzyme in determining the levels of triacylglycerols in seed oils $[58,59]$. Burgal et al. [58] demonstrated that coexpressing the castor bean DGAT2 gene with the castor FA 12 hydroxylase resulted in almost double the levels of hydroxylated fatty acids in neutral lipids (up to $30 \%$ of total, compared with $17 \%$ in the absence of DGAT2). In our study, most of the variations observed in the coding regions are either insertion or deletion of 
$3 \mathrm{bp}$ or multiple of three that represent codon usage which either leads to shift in reading frame or functional mutation that are expected to be related to oil content. Thus, the sequence variations identified in fatty acid biosynthesis genes in this study can be tested for their functional role in altering content and composition of seed oil in Jatropha.

\section{Conclusion}

Comparative genomics, for gene structures and coding sequence variations, was performed on 261 genes involved in fatty acids biosynthesis, TAG synthesis, and oil bodies formation in four oil seed plant species, Arabidopsis, Brassica rapa, castor bean, and soybean to understand whether differences in gene structures or coding sequence determine preferential biosynthesis of higher amounts of particular fatty acids and their contents in the seeds of different plant species. Overall comparative gene structure of fatty acid biosynthesis related genes provided an insight to improve oil quality for biodiesel by exploiting the variations for engineering FAD5, FAD6, and FatB genes to enhance the content of saturated fatty acids. The variations in FAD2, FAD3, Stearoyl desaturase, DGAT-1, and DGAT-2 will be helpful to enhance the oil content in plants. The close relationship between genes under study would be helpful for comparative genomics to study these genes in related species for oil content modification.

\section{References}

[1] D. Antoni, V. V. Zverlov, and W. H. Schwarz, "Biofuels from microbes," Applied Microbiology and Biotechnology, vol. 77, no. 1, pp. 23-35, 2007.

[2] F. Ma and M. A. Hanna, "Biodiesel production: a review," Bioresource Technology, vol. 70, no. 1, pp. 1-15, 1999.

[3] B. J. Nikolau, J. B. Ohlrogge, and E. S. Wurtele, "Plant biotincontaining carboxylases," Archives of Biochemistry and Biophysics, vol. 414, no. 2, pp. 211-222, 2003.

[4] K. M. Mayer and J. Shanklin, "Identification of amino acid residues involved in substrate specificity of plant acyl-ACP thioesterases using a bioinformatics-guided approach," $B M C$ Plant Biology, vol. 7, article 1, 2007.

[5] M. R. Pollard, L. Anderson, C. Fan, D. J. Hawkins, and H. M. Davies, "A specific acyl-ACP thioesterase implicated in medium-chain fatty acid production in immature cotyledons of Umbellularia californica," Archives of Biochemistry and Biophysics, vol. 284, no. 2, pp. 306-312, 1991.

[6] J. J. Salas and J. B. Ohlrogge, "Characterization of substrate specificity of plant FatA and FatB acyl-ACP thioesterases," Archives of Biochemistry and Biophysics, vol. 403, no. 1, pp. 2534, 2002.

[7] J. Okuley, J. Lightner, K. Feldmann, N. Yadav, E. Lark, and J. Browse, "Arabidopsis FAD2 gene encodes the enzyme that is essential for polyunsaturated lipid synthesis," Plant Cell, vol. 6, no. 1, pp. 147-158, 1994.

[8] W. D. Hitz, T. J. Carlson, J. R. Booth, A. J. Kinney, K. L. Stecca, and N. S. Yadav, "Cloning of a higher-plant plastid omega-6 fatty acid desaturase cDNA and its expression in a cyanobacterium," Plant Physiology, vol. 105, no. 2, pp. 635641, 1994.
[9] D. W. Reed, U. A. Schafer, and P. S. Covello, "Characterization of the Brassica napus extraplastidial linoleate desaturase by expression in Saccharomyces cerevisiae," Plant Physiology, vol. 122, no. 3, pp. 715-720, 2000.

[10] K. Iba, S. Gibson, T. Nishiuchi et al., "A gene encoding a chloroplast $\omega-3$ fatty acid desaturase complements alterations in fatty acid desaturation and chloroplast copy number of the fad7 mutant of Arabidopsis thaliana," Journal of Biological Chemistry, vol. 268, no. 32, pp. 24099-24105, 1993.

[11] S. Cases, S. J. Smith, Y. W. Zheng et al., "Identification of a gene encoding an acyl CoA:diacylglycerol acyltransferase, a key enzyme in triacylglycerol synthesis," Proceedings of the National Academy of Sciences of the United States of America, vol. 95, no. 22, pp. 13018-13023, 1998.

[12] K. D. Lardizabal, J. T. Mai, N. W. Wagner, A. Wyrick, T. Voelker, and D. J. Hawkins, "DGAT2 is a new diacylglycerol acyltransferase gene family. Purification, cloning, and expression in insect cells of two polypeptides from Mortierella ramanniana with diacylglycerol acyltransferase activity," Journal of Biological Chemistry, vol. 276, no. 42, pp. 38862-38869, 2001.

[13] A. Serdari, E. Lois, and S. Stournas, "Impact of esters of monoand dicarboxylic acids on diesel fuel quality," Industrial and Engineering Chemistry Research, vol. 38, no. 9, pp. 3543-3548, 1999.

[14] X. Hu, M. S. Gilbert, M. Gupta, and S. A. Thompson, "Mapping of the loci controlling oleic and linolenic acid contents and development of $\mathrm{fad} 2$ and fad 3 allele-specific markers in canola (Brassica napus L.)," Theoretical and Applied Genetics, vol. 113, no. 3, pp. 497-507, 2006.

[15] P. Zhang, J. W. Burton, R. G. Upchurch, E. Whittle, J. Shanklin, and R. E. Dewey, "Mutations in a ${ }^{9}$-stearoyl-ACPdesaturase gene are associated with enhanced stearic acid levels in soybean seeds," Crop Science, vol. 48, no. 6, pp. 23052313, 2008.

[16] Y. López, H. L. Nadaf, O. D. Smith, J. P. Connell, A. S. Reddy, and A. K. Fritz, "Isolation and characterization of the $\Delta 12-$ fatty acid desaturase in peanut (Arachis hypogaea L.) and search for polymorphisms for the high oleate trait in Spanish market-type lines," Theoretical and Applied Genetics, vol. 101, no. 7, pp. 1131-1138, 2000.

[17] K. D. Bilyeu, L. Palavalli, D. A. Sleper, and P. R. Beuselinck, "Mutations in soybean microsomal omega-3 fatty acid desaturase genes reduce linolenic acid concentration in soybean seeds," Crop Science, vol. 45, no. 5, pp. 1830-1836, 2005.

[18] B. K. Ha, M. J. Monteros, and H. R. Boerma, "Development of SNP assays associated with oleic acid QTLs in N00-3350 soybean," Euphytica, vol. 176, no. 3, pp. 403-415, 2010.

[19] X. Yang, Y. Guo, J. Yan et al., "Major and minor QTL and epistasis contribute to fatty acid compositions and oil concentration in high-oil maize," Theoretical and Applied Genetics, vol. 120, no. 3, pp. 665-678, 2010.

[20] A. C. Bruner, S. Jung, A. G. Abbott, and G. L. Powell, "The naturally occurring high oleate oil character in some peanut varieties results from reduced oleoyl-PC desaturase activity from mutation of aspartate 150 to asparagine," Crop Science, vol. 41, no. 2, pp. 522-526, 2001.

[21] P. Zheng, W. B. Allen, K. Roesler et al., "A phenylalanine in DGAT is a key determinant of oil content and composition in maize," Nature Genetics, vol. 40, no. 3, pp. 367-372, 2008.

[22] E. Bachlava, R. E. Dewey, J. Auclair, S. Wang, J. W. Burton, and A. J. Cardinal, "Mapping genes encoding microsomal $\omega-6$ desaturase enzymes and their cosegregation with QTL 
affecting oleate content in soybean," Crop Science, vol. 48, no. 2, pp. 640-650, 2008.

[23] T. Anai, T. Yamada, T. Kinoshita, S. M. Rahman, and Y. Takagi, "Identification of corresponding genes for three low$\alpha$-linolenic acid mutants and elucidation of their contribution to fatty acid biosynthesis in soybean seed," Plant Science, vol. 168, no. 6, pp. 1615-1623, 2005.

[24] K. Aghoram, R. F. Wilson, J. W. Burton, and R. E. Dewey, "A mutation in a 3-keto-acyl-ACP synthase II gene is associated with elevated palmitic acid levels in soybean seeds," Crop Science, vol. 46, no. 6, pp. 2453-2459, 2006.

[25] M. M. Spencer, V. R. Pantalone, E. J. Meyer, D. Landau-Ellis, and D. L. Hyten Jr., "Mapping the Fas locus controlling stearic acid content in soybean," Theoretical and Applied Genetics, vol. 106, no. 4, pp. 615-619, 2003.

[26] B. Pérez-Vich, A. J. Leon, M. Grondona, L. Velasco, and J. M. Fernández-Martínez, "Molecular analysis of the high stearic acid content in sunflower mutant CAS-14," Theoretical and Applied Genetics, vol. 112, no. 5, pp. 867-875, 2006.

[27] A. J. Cardinal, J. W. Burton, A. M. Camacho-Roger, J. H. Yang, R. F. Wilson, and R. E. Dewey, "Molecular analysis of soybean lines with low palmitic acid content in the seed oil," Crop Science, vol. 47, no. 1, pp. 304-310, 2007.

[28] Y. Li, F. Beisson, M. Pollard, and J. Ohlrogge, "Oil content of Arabidopsis seeds: the influence of seed anatomy, light and plant-to-plant variation," Phytochemistry, vol. 67, no. 9, pp. 904-915, 2006.

[29] L. Velasco and H. C. Becker, "Estimating the fatty acid composition of the oil in intact-seed rapeseed (Brassica napus L.) by near-infrared reflectance spectroscopy," Euphytica, vol. 101, no. 2, pp. 221-230, 1998.

[30] L. C. D. S. Ramos, J. S. Tango, A. Savi, and N. R. Leal, "Variability for oil and fatty acid composition in castorbean varieties," Journal of the American Oil Chemists' Society, vol. 61, no. 12, pp. 1841-1843, 1984.

[31] N. K. Sangwan, K. Gupta, and K. S. Dhindsa, "Fatty acid composition of developing soybeans," Journal of Agricultural and Food Chemistry, vol. 34, no. 3, pp. 415-417, 1986.

[32] G. M. Rubin, M. D. Yandell, J. R. Wortman et al., "Comparative genomics of the eukaryotes," Science, vol. 287, no. 5461, pp. 2204-2215, 2000.

[33] P. Tanhuanpää, J. Vilkki, and M. Vihinen, "Mapping and cloning of FAD2 gene to develop allele-specific PCR for oleic acid in spring turnip rape (Brassica rapa ssp. oleifera)," Molecular Breeding, vol. 4, no. 6, pp. 543-550, 1998.

[34] M. A. Smith, H. Moon, G. Chowrira, and L. Kunst, "Heterologous expression of a fatty acid hydroxylase gene in developing seeds of Arabidopsis thaliana," Planta, vol. 217, no. 3, pp. 507516, 2003.

[35] A. Sánchez-García, A. J. Moreno-Pérez, A. M. Muro-Pastor, J. J. Salas, R. Garcés, and E. Martínez-Force, "Acyl-ACP thioesterases from castor (Ricinus communis L.): an enzymatic system appropriate for high rates of oil synthesis and accumulation," Phytochemistry, vol. 71, no. 8-9, pp. 860-869, 2010.

[36] V. Andrianov, N. Borisjuk, N. Pogrebnyak et al., "Tobacco as a production platform for biofuel: overexpression of arabidopsis DGAT and LEC2 genes increases accumulation and shifts the composition of lipids in green biomass," Plant Biotechnology Journal, vol. 8, no. 3, pp. 277-287, 2010.

[37] Z. Dimov and C. Mollers, "Genetic variation for saturated fatty acid content in a collection of European winter oilseed rape material (Brassica napus)," Plant Breeding, vol. 129, no. 1, pp. 82-86, 2010.

[38] R. Singh, S. G. Tan, J. M. Panandam et al., "Mapping quantitative trait loci (QTLs) for fatty acid composition in an interspecific cross of oil palm," BMC Plant Biology, vol. 9, pp. 114-133, 2009.

[39] X. Hu, M. Sullivan-Gilbert, M. Gupta, and S. A. Thompson, "G-to-A mutation at a 5_splice site of fad3c caused impaired splicing in a low linolenic mutant of canola (Brassica napus L.)," Plant Biotechnology, vol. 24, no. 4, pp. 397-400, 2007.

[40] F. Beisson, A. Koo, S. Ruuska et al., "Arabidopsis genes involved in acyl lipid metabolism. A 2003 census of the candidates, a study of the distribution of expressed sequence tags in organs, and a web-based database," Plant Physiology, vol. 132, no. 2, pp. 681-697, 2003.

[41] S. Mekhedov, I. O. De de, and J. Ohlrogge, "Toward a functional catalog of the plant genome. A survey of genes for lipid biosynthesis," Plant Physiology, vol. 122, no. 2, pp. 389401, 2000.

[42] J. Ohlrogge and J. Browse, "Lipid biosynthesis," Plant Cell, vol. 7, no. 7, pp. 957-970, 1995.

[43] J. Yu, S. Hu, J. Wang et al., "A draft sequence of the rice genome (Oryza sativa L. ssp. indica)," Science, vol. 296, no. 5565, pp. 79-92, 2002.

[44] S. A. Goff, D. Ricke, T. H. Lan et al., "A draft sequence of the rice genome (Oryza sativa L. ssp. japonica)," Science, vol. 296, no. 5565, pp. 92-100, 2002.

[45] A. M. Krill, M. Kirst, L. V. Kochian, E. S. Buckler, and O. A. Hoekenga, "Association and linkage analysis of aluminum tolerance genes in maize," Plos One, vol. 5, no. 4, Article ID e9958, 2010.

[46] M. Bevan, I. Bancroft, E. Bent et al., "Analysis of $1.9 \mathrm{Mb}$ of contiguous sequence from chromosome 4 of Arabidopsis thaliana," Nature, vol. 391, no. 6666, pp. 485-488, 1998.

[47] Z. Tian, Q. Qian, Q. Liu et al., "Allelic diversities in rice starch biosynthesis lead to a diverse array of rice eating and cooking qualities," Proceedings of the National Academy of Sciences of the United States of America, vol. 106, no. 51, pp. 21760-21765, 2009.

[48] X. M. Bao and J. Ohlrogge, "Supply of fatty acid is one limiting factor in the accumulation of triacylglycerol in developing embryos," Plant Physiology, vol. 120, no. 4, pp. 1057-1062, 1999.

[49] J. J. Thelen and J. B. Ohlrogge, "Metabolic engineering of fatty acid biosynthesis in plants," Metabolic Engineering, vol. 4, no. 1, pp. 12-21, 2002.

[50] K. Roesler, D. Shintani, L. Savage, S. Boddupalli, and J. Ohlrogge, "Targeting of the Arabidopsis homomeric acetylcoenzyme A carboxylase to plastids of rapeseeds," Plant Physiology, vol. 113, no. 1, pp. 75-81, 1997.

[51] A. Jones, H. M. Davies, and T. A. Voelker, "Palmitoyl-acyl carrier protein (ACP) thioesterase and the evolutionary origin of plant acyl-ACP thioesterases," The Plant Cell, vol. 7, no. 3, pp. 359-371, 1995.

[52] T. A. Voelker, T. R. Hayes, A. M. Cranmer, J. C. Turner, and H. M. Davies, "Genetic engineering of a quantitative trait: metabolic and genetic parameters influencing the accumulation of laurate in rapeseed," Plant Journal, vol. 9, no. 2, pp. 229-241, 1996.

[53] P. Dormann, T. A. Voelker, and J. B. Ohlrogge, "Accumulation of palmitate in Arabidopsis mediated by the acyl-acyl carrier protein thioesterase FATB1," Plant Physiology, vol. 123, no. 2, pp. 637-643, 2000. 
[54] T. Buhr, S. Sato, F. Ebrahim et al., "Ribozyme termination of RNA transcripts down-regulate seed fatty acid genes in transgenic soybean," Plant Journal, vol. 30, no. 2, pp. 155-163, 2002.

[55] G. Bonaventure, J. J. Salas, M. R. Pollard, and J. B. Ohlrogge, "Disruption of the FATB gene in Arabidopsis demonstrates an essential role of saturated fatty acids in plant growth," Plant Cell, vol. 15, no. 4, pp. 1020-1033, 2003.

[56] E. Akbar, Z. Yaakob, S. K. Kamarudin, M. Ismail, and J. Salimon, "Characteristic and composition of Jatropha curcas oil seed from Malaysia and its potential as biodiesel feedstock feedstock," European Journal of Scientific Research, vol. 29, no. 3, pp. 396-403, 2009.

[57] A. J. Kinney, "Genetic engineering of oilseeds for desired traits," in Genetic Engineering, J. K. Setlow, Ed., vol. 19, pp. 149-166, Plenum Press, New York, NY, USA, 1997.

[58] J. Burgal, J. Shockey, C. Lu et al., "Metabolic engineering of hydroxy fatty acid production in plants: RcDGAT2 drives dramatic increases in ricinoleate levels in seed oil," Plant Biotechnology Journal, vol. 6, no. 8, pp. 819-831, 2008.

[59] M. Venegas-Calerón, O. Sayanova, and J. A. Napier, "An alternative to fish oils: metabolic engineering of oil-seed crops to produce omega-3 long chain polyunsaturated fatty acids," Progress in Lipid Research, vol. 49, no. 2, pp. 108-119, 2010. 

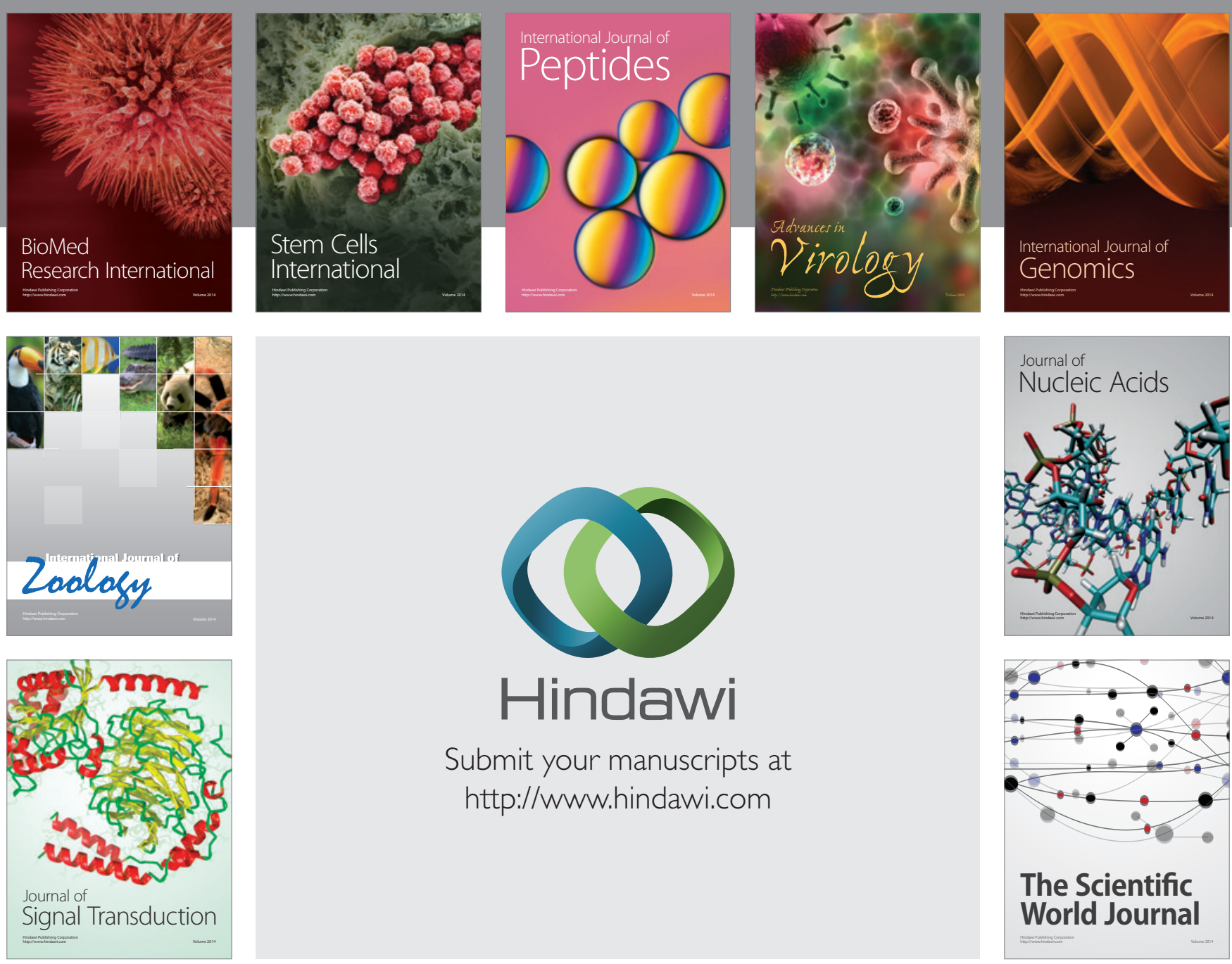

Submit your manuscripts at

http://www.hindawi.com
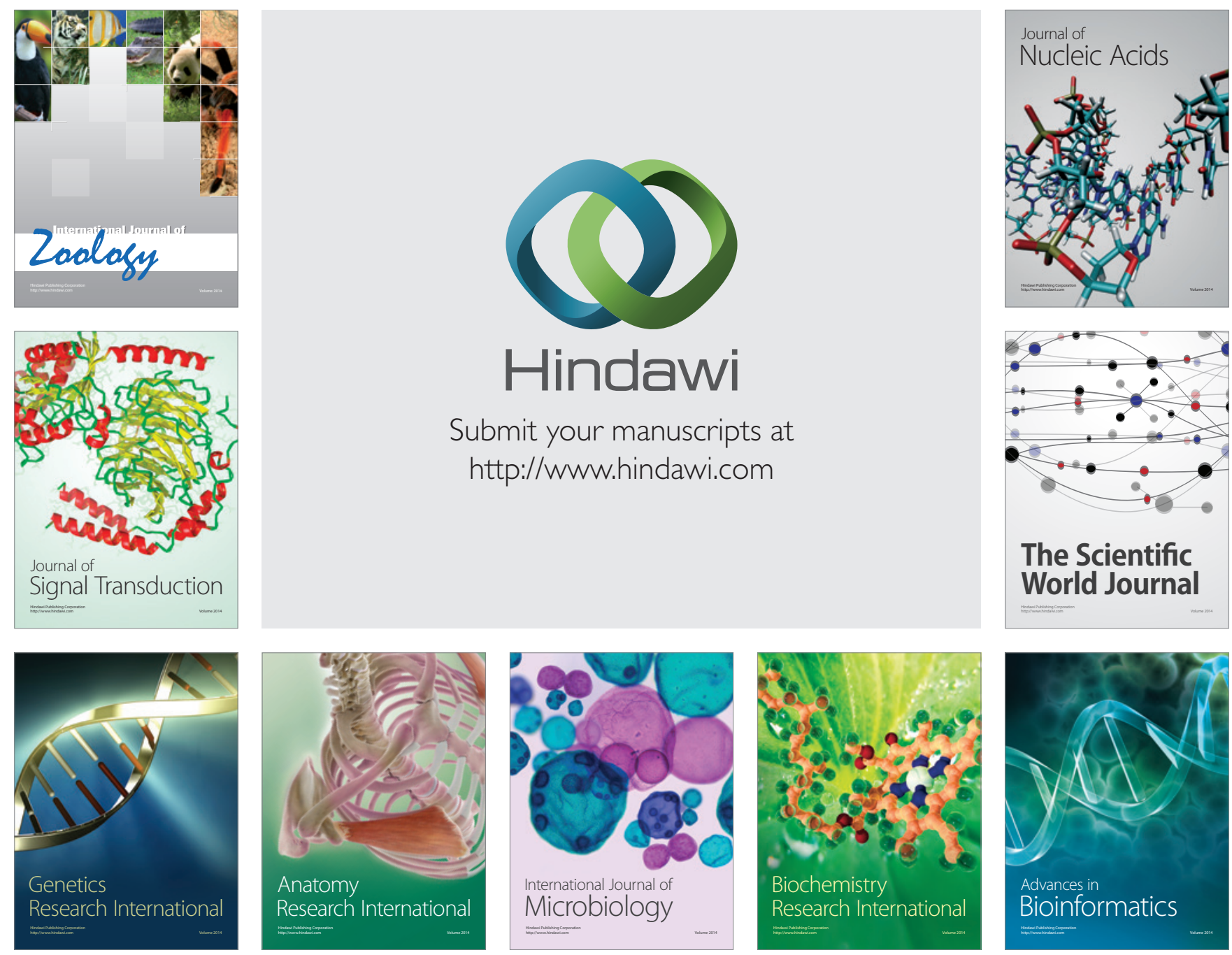

The Scientific World Journal
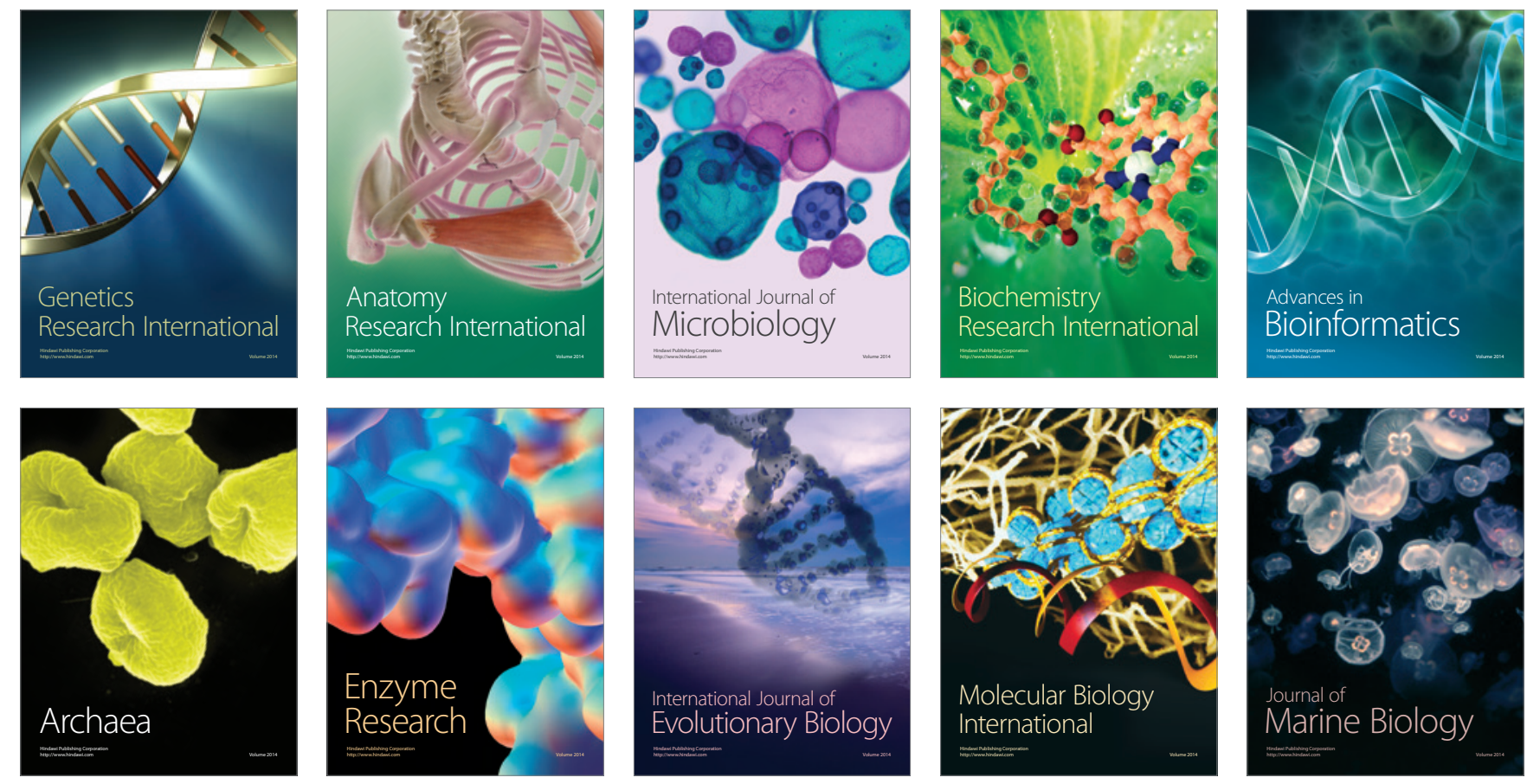